\title{
EDITORIAL $\boldsymbol{H}$ VULNERABLE POPULATIONS
}

\section{Ensuring Canada's first dementia strategy is not shelved and forgotten}

\author{
Nathan M. Stall MD, Pauline Tardif BSocSc, Samir K. Sinha MD DPhil
}

Cite as: CMAJ 2019 August 6;191:E851-2. doi: 10.1503/cmaj.190929

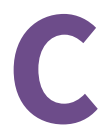

anada has released its first national dementia strategy with a 5-year $\$ 50$-million funding commitment. ${ }^{1}$ The strategy outlines Canada's priorities for dementia, including national objectives to prevent dementia, advance therapies, and improve the quality of life of people living with dementia and their caregivers. The Canadian strategy is aligned with existing national strategies from all other $\mathrm{G} 7$ countries and has notable strengths including a focus on women, caregivers, social isolation and populations facing barriers to equitable care such as Indigenous and LGBTQ2S communities. ${ }^{2}$ To deliver on its bold vision of "a Canada in which all people living with dementia and caregivers are valued and supported," long-term political, financial and societal commitments will be required. ${ }^{1}$

The effect of dementia on Canadians is staggering. While there are currently more than 564000 Canadians living with dementia with estimated annual total health care system and out-of-pocket costs of $\$ 10.4$ billion, these figures are projected to at least double by 2031 as Canadians continue to age. ${ }^{3}$ To be successful in reducing these effects, Canada's national strategy can learn from its own provinces and other countries that have struggled to meet the objectives of their dementia strategies because of limited political commitment beyond the initial announcement, insufficient funding, unclear targets and vague implementation plans. ${ }^{2}$

The advancement of dementia research will also be essential. Existing priorities for global dementia research have been criticized for being uninformed by people living with dementia and their caregivers, and for being too prescriptive when considering that dementia remains a progressive and incurable disease for which a complete understanding of its pathophysiology and effective therapies to stop the progression are lacking. ${ }^{1,4}$

The national strategy for Canada encourages a more holistic approach to dementia research with public-private and international partnerships to maximize funding and impact. ${ }^{1}$ Its research priorities include advancing our fundamental understanding of dementia, developing effective pharmacologic and nonpharmacologic approaches, and innovating better ways to support people living with dementia and their caregivers. ${ }^{1}$ The strategy will benefit from greater clarity around future resources, roles and responsibilities, as well as clear timelines and robust metrics.
It is likely that the $\$ 50$-million commitment will be inadequate to meet the national strategy's objectives. The strategy, for example, suggests a benchmark annual investment in dementia research that exceeds $1 \%$ of dementia care costs - based on 2016 estimates, this would require more than $\$ 100$ million in annual research funding. ${ }^{1,3}$ However, just $5 \%$ of the budget for the Canadian Institutes of Health Research (i.e., \$214 million over the last 10 years) has been invested in dementia research, and public research funding for dementia worldwide is at the level of $10 \%$ of cancer research. ${ }^{5,6}$ The recent allocation of $\$ 46$ million over the next 5 years for the Canadian Consortium on Neurodegeneration in Aging will help to advance the research agenda, but a large funding gap persists. ${ }^{7}$

The national dementia strategy also recognizes that eliminating stigma is a key challenge to its successful implementation. ${ }^{1}$ People living with dementia often lead more hidden and isolated lives because of shame and the fear of negative reactions and lack of acceptance from others. ${ }^{6}$ Dementia is still wrongly stereotyped as a normal part of ageing by both the public and practitioners, contributing to less than 1 in 4 people with dementia receiving a diagnosis worldwide. ${ }^{1,6}$ Stigmatization extends to the Canadian health care system, where people living with dementia experience delays or barriers to equitable care. ${ }^{1,6}$

Overcoming stigma is seen by many as the first key step in global efforts against dementia, but making meaningful progress has been challenging. ${ }^{2,6}$ Future efforts must recognize and target the "double stigma" of ageism and dementia-related discrimination, and should also address existing gender biases. ${ }^{6}$ Women account for two-thirds of all older Canadians living with dementia and for most of the unpaid family and friend caregivers. ${ }^{1}$

The current state of dementia has parallels to the one that confronted HIV/AIDS in the early 1980 s. $^{6}$ On the heels of incredible advocacy efforts that applied moral and political pressure to governments, clinicians and researchers worldwide, HIV/AIDS was transformed from a highly stigmatized and incurable disease into a normalized and treatable chronic condition. ${ }^{6}$ Achieving the same for Canadians who are and will be affected by dementia is possible but only with sustained political will, adequate funding, measurable targets and a commitment from all Canadians to achieve the goals of our new national strategy. 


\section{References}

1. A dementia strategy for Canada: together we aspire. Ottawa: Public Health Agency of Canada; 2019. Available: www.canada.ca/en/public-health/services/ publications/diseases-conditions/dementia-strategy.html (accessed 2019 June 17).

2. Chow S, Chow R, Wan A, et al. National dementia strategies: What should Canada learn? Can Geriatr J 2018;21:173-209.

3. Chambers LW, Bancej C, McDowell I, editors. Prevalence and monetary costs of dementia in Canada. Toronto: Alzheimer Society of Canada; 2016. Available: https://alzheimer.ca/sites/default/files/files/national/statistics/ prevalenceandcostsofdementia_en.pdf (accessed 2019 July 5).

4. Schneider LS. WHO's dementia strategy: A prescription for failure? Lancet Neurol 2016;15:1202-3.
5. Alzheimer's research in Canada [infographic]. Ottawa: Canadian Institutes of Health Research; 2013. Available: https://alzheimer.ca/sites/default/files/images/ national/get\%20involved/raise\%20your\%20voice/cihr_alzheimer_infographic_e. pdf (accessed 2019 July 11).

6. Batsch NL, Mittelman MS. World Alzheimer Report 2012: overcoming the stigma of dementia. London (UK): Alzheimer's Disease International; 2012. Available: www. alz.co.uk/research/WorldAlzheimerReport2012.pdf (accessed 2019 July 9).

7. Government of Canada reinvests in the Canadian Consortium on Neurodegeneration in Aging. Ottawa: Canadian Institutes of Health Research; 2019. Available: www.canada.ca/en/institutes-health-research/news/2019/06/government-of -canada-reinvests-in-the-canadian-consortium-on-neurodegeneration-in-aging. html (accessed 2019 July 11).
Competing interests: Pauline Tardif is the CEO of the Alzheimer Society of Canada, which has received grants from the Public Health Agency of Canada funding regional consultations to help inform the National Dementia Strategy and to support the Dementia Friends program. Pauline Tardif is a co-chair and Samir Sinha is a member of the Ministerial Advisory Board on Dementia, which advises Canada's minister of health on dementia and provided guidance for the development of the National Dementia Strategy. See www.cmaj.ca/site/misc/cmaj_staff.xhtml for Nathan Stall.
Affiliations: Department of Medicine (Stall, Sinha), and Institute of Health Policy, Management and Evaluation (Stall, Sinha), University of Toronto, Toronto, Ont.; Sinai Health System (Stall, Sinha) and Women's College Hospital (Stall), Toronto, Ont.; Alzheimer Society of Canada (Tardif), Toronto, Ont.; Associate editor (Stall), CMAJ.

Correspondence to: CMAJ editor, cmaj@cmajgroup.ca 